\title{
Chemical Heterogeneity of Deposits Formed in the Flocculant Flow From Crude Oil, According to FTIR Microscopy and Chemical Imaging
}

\author{
A. S. Shalygin ${ }^{a, *}$, E. S. Milovanov ${ }^{a}$, S. S. Yakushkin ${ }^{a}$, and O. N. Martyanov ${ }^{a}$ \\ ${ }^{a}$ Boreskov Institute of Catalysis, Siberian Branch of Russian Academy of Sciences, Novosibirsk, 630090 Russia \\ *e-mail: shas@catalysis.ru
}

Received April 21, 2021; revised July 8, 2021; accepted August 3, 2021

\begin{abstract}
Asphaltene-containing deposits formed on the $\mathrm{CaF}_{2}$ window induced by $n$-heptane flow in a microfluidic device have been investigated using an IR microscope and an imaging macro chamber (IMAC) with FPA detection. This is the first example of the ex situ infrared imaging of the deposits from crude oil formed under dynamic conditions of flocculant flow. It has been shown that fast aggregation of asphaltenes in $n$-heptane flow leads to the formation of deposit rich in heteroatom-containing functional groups: $(\mathrm{O}-\mathrm{H}, \mathrm{N}-\mathrm{H}, \mathrm{C}=\mathrm{O}, \mathrm{C}-\mathrm{O}$, and $\mathrm{S}=\mathrm{O})$.
\end{abstract}

Keywords: FTIR microscopy, FTIR spectroscopic imaging, chemical imaging, oil, asphaltenes, microfluidic devices

DOI: $10.1134 /$ S0965544121090127

Petroleum asphaltenes are alkylated polycyclic aromatic compounds containing heteroatoms such as sulfur, oxygen, and nitrogen and certain metals such as vanadium and nickel. Asphaltenes are the heaviest nondistillable fractions of crude oil classified according to their solubility. A series of experimental studies have confirmed the colloidal behavior of asphaltenes in organic media [1-3]. Strong adhesion of asphaltenes to metal surfaces $[4,5]$ is a serious issue in crude oil transportation over the pipelines. Asphaltenes can precipitate and form deposits during oil extraction (in oil reservoirs and wells) and during transportation (in pipelines and refinery installations). Moreover, the presence of asphaltenes can lead to the formation of dense "water in oil" emulsions preventing the separation of oil/gas and water $[6,7]$. Asphaltenes turn unstable upon the change in solubility or solvent power of the medium, pressure and/or temperature during oil extraction and depletion of the reservoir, oil composition due to solvent injection to enhance the production rate or mixing of different sorts of oil [8].

The interest to the use of microfluidic technologies in the study of asphaltenes has emerged over two recent decades, and the related miniature devices have been developed and tested [9]. Channels of the microfluidic devices can be manufactures using a range of materials (glass, metals, polymers, etc.); channel inner surface coating with other material can also be used [10]. For example, the interaction of asphaltenes with glass surface have been considered as an indirect factor of their deposition in the pores of an oil reservoir basing on the results of the experiments on deposition of asphaltenes in a glass microcapillary $[11,12]$. Simultaneous application of microfluidic methods and optical fluorescent microscopy has demonstrated the prospects of microfluidic technologies for the determination of solubility and diffusivity of toluene, $\mathrm{CO}_{2}$, and propane in bitumen [13-15].

Glass microdevices have been widely used in visualization of multiphase system in a flow containing petroleum components. For example, Bowden et al. [16] have developed a microfluidic device in which the separation of asphaltenes from oil has occurred continuously over several seconds upon mixing of crude oil with $n$-hexane. Sieben et al. [17] have used optical detection methods for investigation of the processes in a microfluidic device and measured the solubility profile of asphaltenes in mixtures of solvent and floccules [18]. Visualization of multiphase flow under high pressure conditions [19] have been 
performed to study the size parameters of the pores during extraction of residual oil with mixing hydrocarbon gases at simultaneous water and gas pumping (SWAG). Using a glass multi-channel microreactor with uniform "pattern" and a high-resolution camera, it has been demonstrated that precipitation of asphaltenes is a multistage process usually controlled by molecular diffusion starting upon the introduction of $n$-heptane, which is a relatively slow process in comparison with deposition [20,21].

In addition to the above-mentioned approaches combining optical and fluorescent microscopy with the use of glass microfluidic devices, there are efficient noninvasive methods of spatial visualization which allow obtaining a detailed information on chemical composition and physico-chemical of the spatially distributed components. Fourier transform infrared (FTIR) spectroscopic imaging (sometimes referred to as "chemical imaging") [22] and magnetic resonance imaging (MRI) methods [23] have appeared extremely effective for the investigation of the aforementioned processes. MRI provides spatial resolution of $10 \mu \mathrm{m}$, which allows the study of the systems at the micrometer level to obtain unique in situ data on the phase stability and physico-chemical processes in real oil samples under different external conditions at different space and time scales. MRI has been used in the studies of aggregation [24], precipitation [25], and segregation [26] of asphaltenes; formation of gas voids [27] and multilayer deposits of paraffin [24] in paraffinrich oil; rheology of heavy oils and model systems [26]; reversibility of certain processes involving asphaltenes depending on their local environment [24].

The original studies on the application of IR spectroscopy published more than 20 years ago have unambiguously demonstrated the correlation of chemical composition of asphaltenes with the oil origin [28-33]. Prof. S. Kazarian [34] was the first to use FTIR spectroscopy with matrix detection under the attenuated total reflection (ATR) conditions to investigate the asphaltenes aggregation. ATR-FTIR spectroscopic imaging is advantageous in that it is a nondestructive analytical method for the study of strongly absorbing objects, does not require sophisticated specimen preparation, and affords chemical information with spatial resolution on the components of the sample [35]. Recent studies [36-39] have demonstrated the application of macro-ATR-FTIR spectroscopy for in situ visualization and chemical description of the deposits formed in crude oil. The mapping method using an FTIR microscope has been mainly used in biology and pharmaceutics [40, 41]. The investigation of oxidized asphaltenes can be marked among scarce reports on spatial visualization using IR microscopy [42].

Our earlier study [43] has been the first to demonstrate the application of FTIR spectroscopic imaging for in situ monitoring of precipitation process of asphaltenes induced by $n$-heptane in a flow using microfluidic devices, which has allowed tracking of the amount and spatial distribution of the chemical components in the system and display the aggregates formation with spatial resolution of several microns. Chemical analysis of the formed deposits has revealed spatial inhomogeneity of the composition of the precipitated asphaltenes: the asphaltenes with different $\mathrm{CH}_{2} / \mathrm{CH}_{3}$ ratios and, hence, differing in length of the alkyl chain are precipitated in sequence which results in the anisotropy of the spatial distribution along the flocculant flow.

In this study, we used the FTIR spectroscopic imaging for the first time to investigate chemical composition and spatial distribution of functional groups in deposits formed from crude oil in a flocculant ( $n$-heptane) flow. We compared and discussed the possibilities of FTIR microscopy and chemical imaging for investigation of complex multicomponent systems (real oils).

\section{EXPERIMENTAL}

Crude oil with the following parameters was studied: density $0.936 \mathrm{~g} / \mathrm{cm}^{3}$; content (wt \%): aromatic hydrocarbons 41.9 , aliphatic hydrocarbons 18.8 , sulfur 2.2, nitrogen 0.38 , asphaltenes 6.0 , tar 8.8. $n$-Heptane ("spectroscopy pure" grade) from Komponent-reaktiv (Russia) was used as received. Deposit of asphaltenes was formed on the surface of $\mathrm{CaF}_{2}$ optical window as described elsewhere [43].

IR-Fourier visualization experiments were performed using a Bruker Vertex 70v spectrometer (Germany), equipped with an imaging macro chamber (IMAC, Bruker Optics) with a $64 \times 64$ focal plane array (FPA) detector and an FTIR microscope (HYPERION 3000). The experimental setup is shown in Fig. 1.

The IMAC camera allowed recording the IR spectra over the 3900 to $1000 \mathrm{~cm}^{-1}$ range with spectral resolution of $8 \mathrm{~cm}^{-1}$. The area probed in transmission mode with the FTA detector was $2.56 \mathrm{~mm} \times 2.56 \mathrm{~mm}$ with a lateral special resolution being $40 \mu \mathrm{m}$ per a pixel. Each spectrum was recorded with 256 scans. The FTIR microscope was equipped with an $\mathrm{MCT}(\mathrm{HgCdTe})$ detector, a $\times 15$ infrared 
objective, and the digital microscope camera (Teledyne Lumenera Infinity). The IR spectra were recorded with $8 \mathrm{~cm}^{-1}$ resolution and 128 scans per a point. The obtained IR spectrum corresponded to the area of $40 \mu \mathrm{m} \times 40 \mu \mathrm{m}$ per a point. The spectra were processed using OPUS 8.5 software (Bruker Optics, Germany). The images were created from the recorded IR spectra by setting the pixels color according to integral absorbance at certain spectral bands and combining the data into a two-dimensional image.

Deposits from oil were obtained using a liquid IR cell with $\mathrm{CaF}_{2}$ optical windows (Pike Technologies, USA). Scheme of the microfluidic device and the method of the deposits formation is displayed in Fig. 2. Each window was $32 \mathrm{~mm}$ in diameter and $3 \mathrm{~mm}$ thick. Standard spacer of the cell was changed with the Teflon spacer having the channels and cavity (Teflon film thickness $100 \mu \mathrm{m}$; channel width $2.5 \mathrm{~mm}$, void width $5 \mathrm{~mm}$ ) The experiments on asphaltenes precipitation in $n$-heptane were performed as follows: the cavity of the microfluidic device was first filled with oil using a micro syringe, and then $n$-heptane was introduced through a system of the microcapillaries at $1 \mathrm{~mL} / \mathrm{h}$ rate, which induced the deposit formation which occurred within $90 \mathrm{~min}$ over the entire cell area. The deposit formed at the $\mathrm{CaF}_{2}$ surface could be used for ex situ investigation after a day, upon evaporation of $n$-heptane from channels and cavity of the microfluidic device. The device setup and method of the asphaltenes deposit formation have been described in detail [43].

\section{RESULTS AND DIFFUSION}

Investigation of the asphaltenes deposit. In this study we compared the methods of chemical imaging using FTIR microscopy and FPA detection using two examples: investigation of the asphaltenes deposit precipitated from a solution in benzene with $n$-heptane

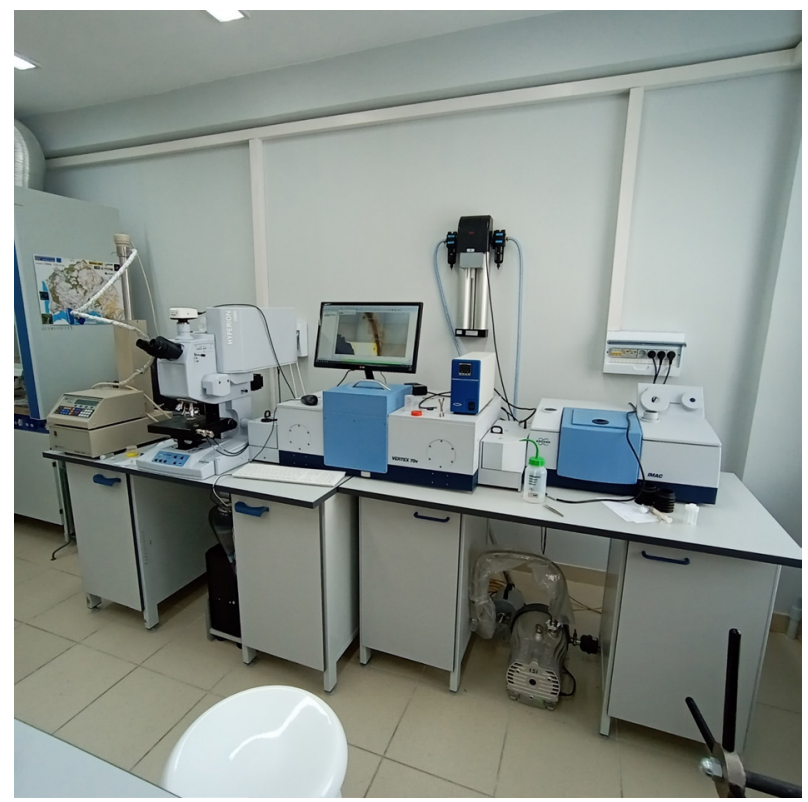

Fig. 1. Vextex 70V FTIR spectrometer with attached HYPERION 3000 FTIR microscope (left) and imaging macro chamber (IMAC) (right).

stream [43] and the deposits precipitated from oil via the same method onto the $\mathrm{CaF}_{2}$ surface.

Figure 3 displays the snapshot of the asphaltenes deposit $(a)$ and FTIR spectroscopic images of spatial distribution of different functional groups in the deposit (rows $b, c$ ). The images were obtained by plotting of the integral intensities of the bands in the IR spectra of the deposit formed in a flow-through regime at 3600-3100, 3000-2800, 1800-1650, 1200-1100, and 1100-980 $\mathrm{cm}^{-1}$, which corresponded to stretching vibration modes of the $\mathrm{O}-\mathrm{H}(\mathrm{N}-\mathrm{H}), \mathrm{C}-\mathrm{H}, \mathrm{C}=\mathrm{O}, \mathrm{C}-\mathrm{O}$, and $\mathrm{S}=\mathrm{O}$ bonds in the hydroxyl (amino), aliphatic $\left(\mathrm{CH}_{3} / \mathrm{CH}_{2} / \mathrm{CH}\right)$, carbonyl, ether, and sulfoxide groups. Row $b$ shows the spectroscopic images obtained in early 2019, and the

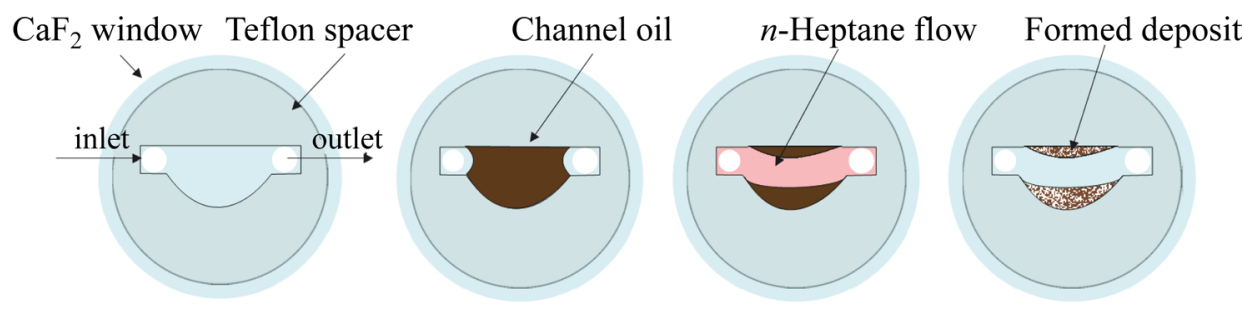

Fig. 2. Scheme of the deposit formation in a flow-through regime (left to right). 


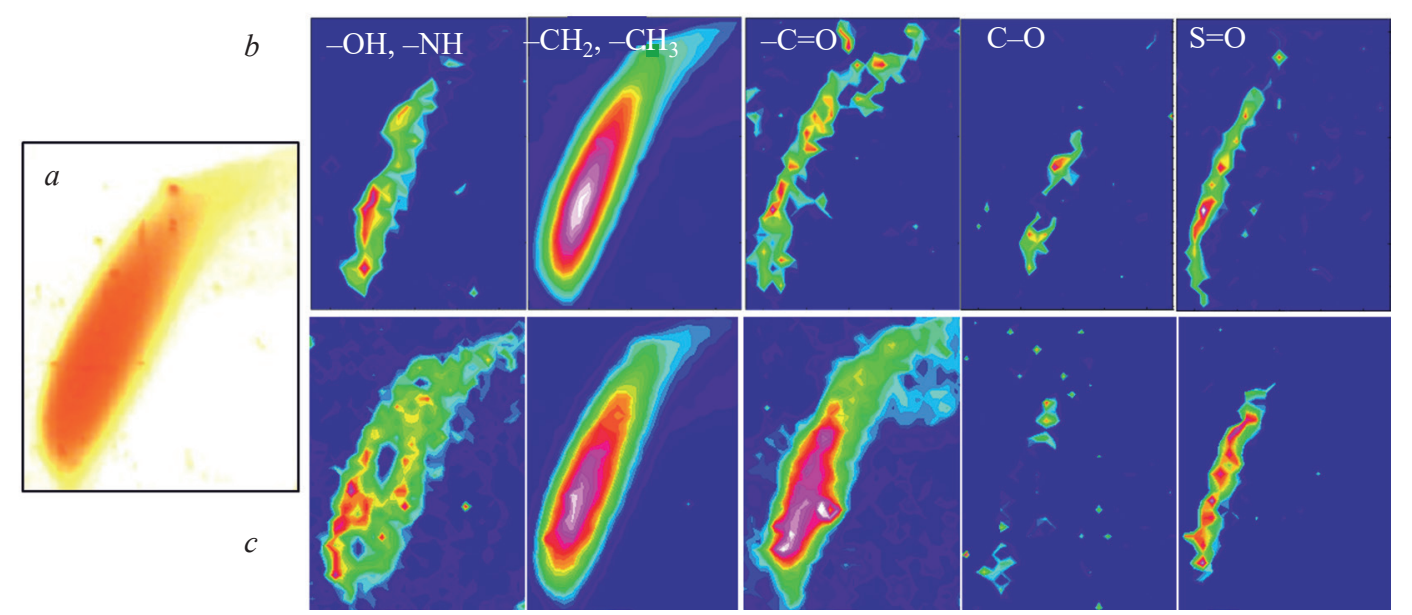

Fig. 3. Snapshot of the asphaltene deposit $(a)$ and FTIR spectroscopic images of spatial distribution of different functional groups in the deposit (rows $b, c$ ). Images $(b)$ were obtained using a freshly prepared deposit in early 2019; images (c) were obtained in early 2021.

images of the same sample obtained in early 2021 are in row $c$, which means 2 years exposition in air between the observations. It is to be seen that repeated examination of the asphaltenes deposit by means of FTIR spectroscopic imaging revealed the multifold increase in the content of hydroxyl and carboxyl groups as well as widening of their localization area. Comparison of the images in rows $b$ and $c$ showed that after two years the hydroxyl groups were observed over the entire specimen surface, whereas they were visualized at the right part of the image in the freshly prepared sample. Surface distribution of the aliphatic groups was not changed, and the carbonyl groups were found over the entire surface after exposure to air. The area of the spatial distribution of the $\mathrm{C}-\mathrm{O}$ groups was narrowed in compare with the images from 2019. It can be said, that the signal intensity has become comparable to the noise level, see the IR microscopy results below. The distribution of the $\mathrm{S}=\mathrm{O}$ was changed, but the evolution could not be considered significant: the $\mathrm{S}=\mathrm{O}$ groups were observed in the left edge of the sediment, and the width of the distribution was increased, along with the signal intensity. Hence, the method of chemical imaging allowed efficient investigation of the change in chemical composition in the petroleum systems and spatial inhomogeneity of of the functional group distribution in the asphaltene-containing deposits upon preparation as well as during aging and degradation.

In contrast to the FPA detection, chemical imaging with an FTIR microscope in the transmission mode consisted in sequential scanning of the image divided into several regions of predefined size. A tunable opaque diaphragm was used to record the spectrum corresponding to the selected specimen region. The asphaltenes deposit part of $520 \times 200 \mu \mathrm{m}$ was divided into 65 parts with grid piece (cell size $40 \times 40 \mu \mathrm{m}$, which corresponded to the resolution in the IMAC experiment). Scanning of the entire region ( 65 spectra recorded with 128 scans each) took about $70 \mathrm{~min}$. Figure 4 displays the visible microscopy snapshot of the deposit with the marked part of the specimen assigned to scanning, along with the spectroscopic images obtained by plotted of integral intensity of the IR bands in the spectra of the deposit at 3600-3100, 3000-2800, 1800-1650, 1200-1100, and $1100-980 \mathrm{~cm}^{-1}$, which corresponded to stretching vibration modes of the $\mathrm{O}-\mathrm{H}(\mathrm{N}-\mathrm{H}), \mathrm{C}-\mathrm{H}, \mathrm{C}=\mathrm{O}, \mathrm{C}-\mathrm{O}$, and $\mathrm{S}=\mathrm{O}$ bonds in the hydroxyl (amino), aliphatic $\left(\mathrm{CH}_{3} /\right.$ $\mathrm{CH}_{2} / \mathrm{CH}$ ), carbonyl, ether, and sulfoxide groups. Spatial distribution of the $\mathrm{CH}_{2}, \mathrm{CH}_{3}$ groups coincided with the shape of the deposit. Spatial distribution of the $\mathrm{C}=\mathrm{O}$ groups revealed wider distribution of the maximum in comparison with that of the aliphatic groups. Spatial distribution of the $\mathrm{O}-\mathrm{H}(\mathrm{N}-\mathrm{H})$ groups showed the maximum to the left of that of the aliphatic groups. Ether groups were not observed in the probed region, the corresponding image showing a single point with the intensity above the noise level. The shape of spatial distribution of the $\mathrm{S}=\mathrm{O}$ groups was more complex in comparison with other groups. The disappearance of the ether groups was assigned to their oxidation into ketones, aldehydes, and other carbonyl compounds, which was 
confirmed by the observed high content of the $\mathrm{C}=\mathrm{O}$ groups (Figs. 3 and 4).

Comparison of the methods of chemical imaging of microscopy applied to the asphaltenes deposit showed that the chemical imaging method allowed much faster scanning of the specimen, to get simultaneously 4096 spectra from the $2.56 \mathrm{~mm} \times 2.56 \mathrm{~mm}$ region (in transmission mode). Productivity of the FTIR microscope was lower, since the spectra were recorded in sequence when using the single-element detector. At the same time, the spectra obtained using the FTIR microscope were of better quality, due to better parameters of the MCT detector (faster recording of a single spectrum, better signal-to-noise ratio, broader spectral range, better sensitivity, higher spectral resolution) and the possibility to adjust the scanned area using a diaphragm and changeable lenses.

Investigation of the deposits from oil. The approach to obtain the asphaltenes deposit in the $n$-heptane flow using the microfluidic device was used for ex situ preparation of the asphaltene-containing deposits from crude oil. Figure 5 displays the snapshot of the part of the deposit obtained via replacement of oil with $n$-heptane flow. The region probed for chemical imaging is marked on the snapshot. Figure 5 also shows the FTIR spectroscopic images of the deposit obtained by plotted of the integral intensity of the bands at 3600-3100, 3000-2800, 1800-1650, 1200-1100, and 1100-980 $\mathrm{cm}^{-1}$, which corresponded to the stretching vibration modes of the $\mathrm{O}-\mathrm{H}(\mathrm{N}-\mathrm{H})$, $\mathrm{C}-\mathrm{H}, \mathrm{C}=\mathrm{O}, \mathrm{C}-\mathrm{O}$, and $\mathrm{S}=\mathrm{O}$ bonds. Similar to the above-

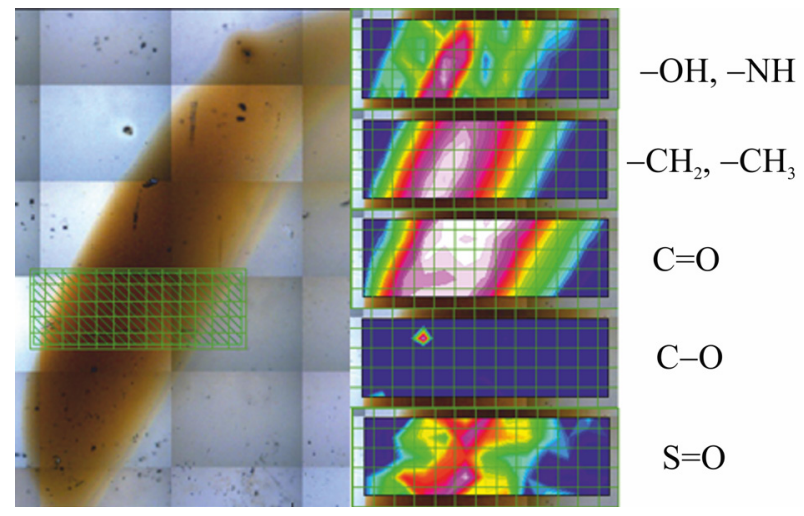

Fig. 4. The visible microscopy snapshot of the asphaltenes deposit formed at the $\mathrm{CaF}_{2}$ window surface with the marked mapping region (left). The images on the right show spectroscopic imaging of spatial distribution of functional groups in the deposit.

described case of the solution of asphaltenes in benzene, oil was put in the channel of the microfluidic device, and then a flow of $n$-heptane was supplied. The deposit was predominantly formed along the channel wall, likely due to higher viscosity of oil. Spatially nonuniform deposit as stripes along the flow direction was formed at the interface between $n$-heptane and oil. Such deposits were formed at the initial stage of the oil contact with $n$-heptane flow. Closer to the walls of the microfluidic device (above the initially formed stripes), the precipitate was formed due to $n$-heptane diffusion into oil. Such mechanism of the precipitate formation has been studied by us earlier [43] during precipitation of asphaltenes from their solution in benzene. The spots, oil residues got between the spacer

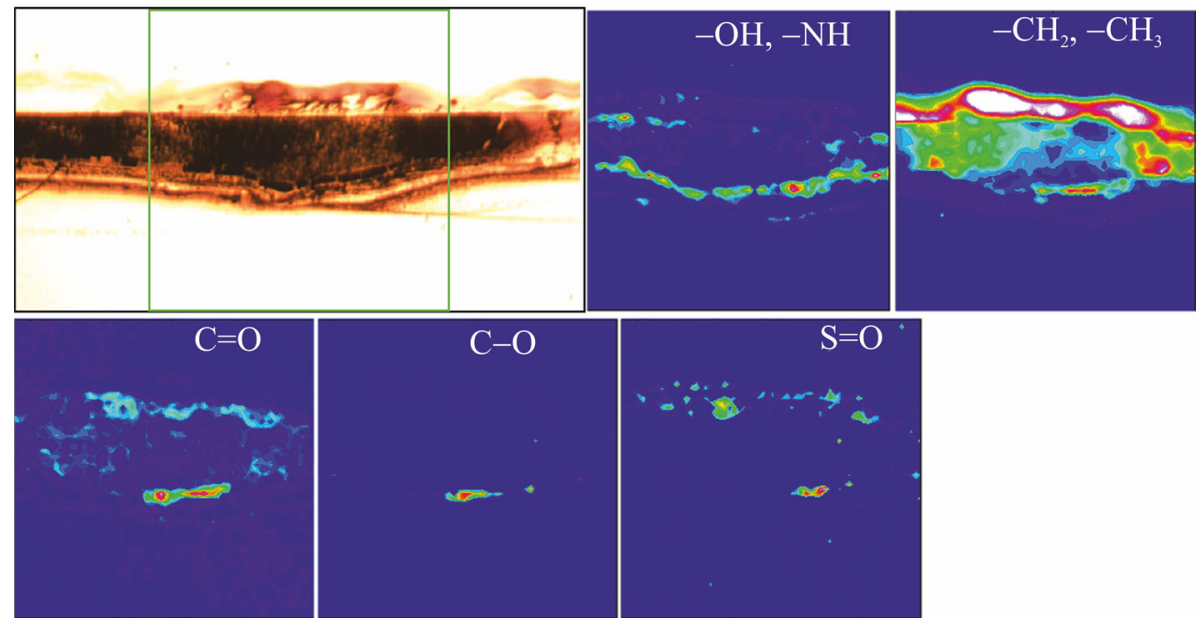

Fig. 5. Snapshot of the deposit formed from oil on the $\mathrm{CaF}_{2}$ window surface and FTIR spectroscopic images of functional groups distribution. 


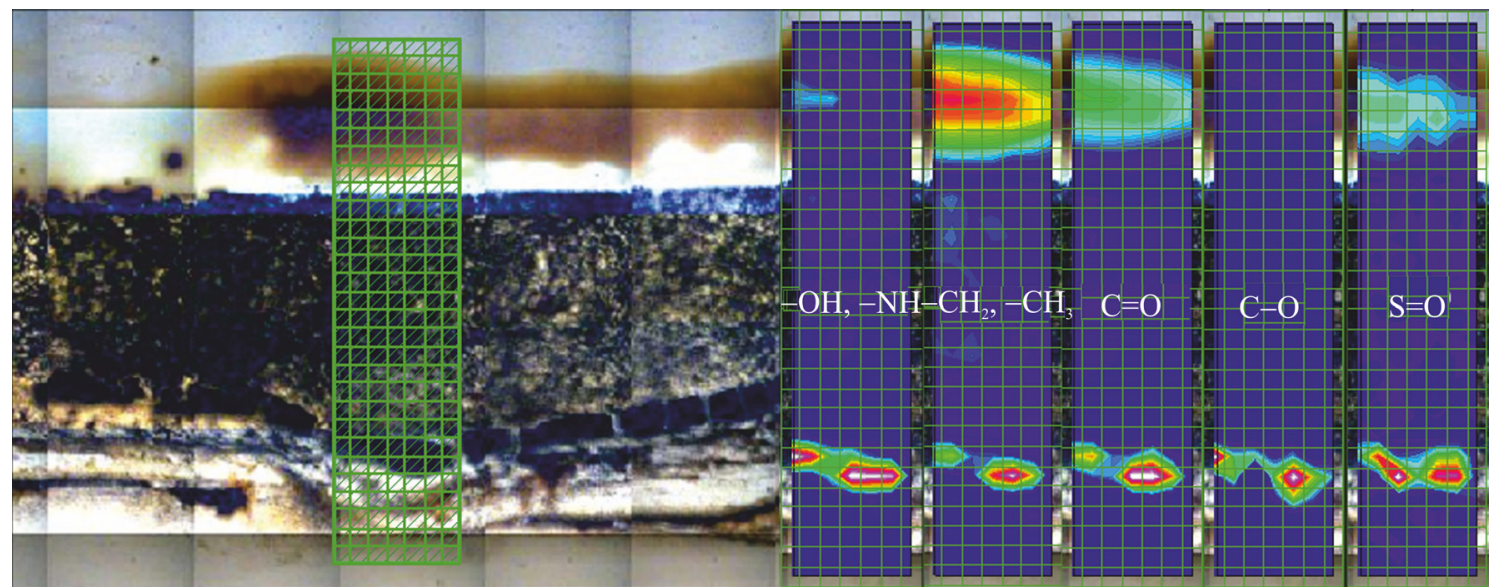

Fig. 6. The visible microscopy snapshot of the deposit formed from oil at the surface of the $\mathrm{CaF}_{2}$ window with $n$-heptane flow, with the marked mapping area (a grid cell corresponds to $40 \mu \mathrm{m} \times 40 \mu \mathrm{m}$ ) and FTIR spectroscopic images of the functional groups over the marked area.

and the fluorite window, were observed above the line corresponding to the microfluidic device wall. The FTIR spectroscopic images of the spatial distribution of the aliphatic showed that the highest intensity of their bands was observed in oil outside of the deposit. The intensity of the aliphatic groups bands in the deposit formed by the flow was higher than those formed via $n$-heptane diffusion.

Considering spatial distribution of the $\mathrm{O}-\mathrm{H}(\mathrm{N}-\mathrm{H})$, $\mathrm{C}-\mathrm{H}, \mathrm{C}=\mathrm{O}, \mathrm{C}-\mathrm{O}$, and $\mathrm{S}=\mathrm{O}$ groups, the highest concentration of those groups was observed in the deposits formed by $n$-heptane flow. That fact shows that the deposit with high content of the heteroatoms functional groups were initially formed from oil in the flocculant flow. That conclusion confirms the results obtained during the study of precipitation of the asphaltenes solution with $n$-heptane flow [43] and precipitation of asphaltenes from the solution and oil under static conditions [37].

The same specimen was investigated using the FTIR microscope. Figure 6 displays the visible microscopy snapshot of the deposit with the mapping area of $1200 \times 280 \mu \mathrm{m}$. The visible microscopy snapshot was composed of several frames obtained automatically and has better resolution in comparison with that obtained in the IMAC experiment (Fig. 5). The obtained snapshot clearly showed the strip of the deposit formed in the $n$-heptane flow, the region of diffuse precipitation, and the spot of oil residue. The FTIR spectroscopic images revealed high content of the functional groups (hydroxyl/amine, carbonyl, and sulfoxide ones) in the deposit formed by the $n$-heptane flow. The use of more sensitive single-element MCT detector (in comparison with the FPA one) gave sharper spectroscopic images. However, even at that resolution which was close to maximum for the IMAC and FTIR microscopy methods no spatial heterogeneity could be observed in the region corresponding to the asphaltene-containing deposits formed by $n$-heptane flow.

\section{CONCLUSIONS}

Herein we investigated the asphaltene-containing deposits formed on the $\mathrm{CaF}_{2}$ window surface in $n$-heptane flow in the microfluidic device using the IR microscope and the imaging macro chamber (IMAC) with FPA detection. This is the first example of chemical imaging of the deposits formed ex situ from crude oil under dynamic conditions of the flocculant flow.

It was shown that the formed asphaltene-containing deposit was oxidized after air exposure, which led to the change in the chemical composition and special redistribution of the components. For example, the FTIR spectroscopic imaging monitoring revealed multiple increase in the content of hydroxyl and carbonyl groups and significant increase in the area of their spatial distribution during aging on air.

The formation of deposit from oil in $n$-heptane flow (i.e. the deposit formed in the kinetic regime at the initial stage of $n$-heptane mixing with oil) was studied. Those deposits were visually denser than the deposits formed during diffusion of $n$-heptane into oil. The 
FTIR spectroscopic imaging data revealed that the $\mathrm{O}-\mathrm{H}$ $(\mathrm{N}-\mathrm{H}), \mathrm{C}-\mathrm{H}, \mathrm{C}=\mathrm{O}, \mathrm{C}-\mathrm{O}$, and $\mathrm{S}=\mathrm{O}$ functional groups were concentrated in the deposits formed under dynamic conditions. That fact suggested that the asphaltenes with high content of the heteroatoms were initially deposited in the $n$-heptane flow. The asphaltenes with low content of heteroatoms were likely carried out by $n$-heptane or precipitated via slow diffusion of $n$-heptane into oil.

Hence, the chemical imaging method could be efficiently used for the investigation of inhomogeneity of spatial distribution of the compounds bearing different functional groups as well as the evolution of chemical composition of the precipitates and petroleum deposits.

Comparison of the methods of chemical imaging (sequential mapping using an FTIR microscope and FPA detection using an imaging macro chamber) demonstrated the advantage of the FPA detection for the investigation of the oil deposit consisting in fast acquisition of many IR spectra of the surface. At the same time, the use of the MCT detector of the FTIR microscope gave better quality of the IR spectra, which is important for the study of strongly absorbing samples.

\section{AUTHOR INFORMATION}

A.S. Shalygin, ORCID: https://orcid.org/0000-0002-74144256

E.S. Milovanov, ORCID: https://orcid.org/0000-00031211-8711

S.S. Yakushkin, ORCID: https://orcid.org/0000-00025107-980X

O.N. Martyanov, ORCIDs: http://orcid.org/0000-00019999-8680

\section{FUNDING}

This study was financially supported by the Russian Science Foundation (project no. 20-79-0018) and performed using the equipment of the "National Center for Investigation of Catalysts" Center for Collective Usage.

\section{CONFLICT OF INTEREST}

The authors declare no conflict of interest requiring disclosure in this article.

\section{OPEN ACCESS}

This article is licensed under a Creative Commons Attribution 4.0 International License, which permits use, sharing, adaptation, distribution and reproduction in any medium or format, as long as you give appropriate credit to the original author(s) and the source, provide a link to the Creative Commons license, and indicate if changes were made. The images or other third party material in this article are included in the article's Creative Commons license, unless indicated otherwise in a credit line to the material. If material is not included in the article's Creative Commons license and your intended use is not permitted by statutory regulation or exceeds the permitted use, you will need to obtain permission directly from the copyright holder. To view a copy of this license, visit http://creativecommons.org/licenses/by/4.0/.

\section{REFERENCES}

1. Forte, E., Taylor, S.E., Adv. Colloid Interface Sci., 2015, vol. 217, pp. 1-12. https://doi.org/10.1016/j.cis.2014.12.002

2. Tuzikov, F.V., Larichev, Y.V., Borisova, L.S., Kozhevnikov, I.V., and Mart'yanov, O.N. Petrol. Chem., 2011, vol. 51, pp. 281-285.

https://doi.org/10.1134/S0965544111040104

3. Larichev, Y.V., Kovalenko, E.Y., and Mart'yanov, O.N., Petrol. Chem., 2019, vol. 59, pp. 1195-1200. https://doi.org/10.1134/S0965544119110100

4. Adams, J.J., Energy Fuels, 2014, vol. 28, pp. 2831-2856. https://doi.org/10.1021/ef500282p

5. Wang, J., Buckley, J.S., and Creek, J.L., J. Dispers. Sci. Technol., 2004, vol. 25, pp. 287-298. https://doi.org/10.1081/DIS-120037697

6. Arab, D., Kantzas, A., and Bryant, S.L., J. Pet. Sci. Eng., 2018, vol. 163, pp. 217-242.

https://doi.org/10.1016/j.petrol.2017.12.091

7. Langevin, D. and Argillier, J.-F., Adv. Colloid Interface Sci., 2016, vol. 233, pp. 83-93.

https://doi.org/10.1016/j.cis.2015.10.005

8. Thomas, S., Oil Gas Sci. Technol. - Rev. l'IFP, 2008, vol. 63, pp. 9-19. https://doi.org/10.2516/ogst:2007060

9. Mozaffari, S., Ghasemi, H., Tchoukov, P., Czarnecki, J., and Nazemifard, N., Energy Fuels, 2021, vol. 35, pp. 9080-9101.

https://doi.org/10.1021/acs.energyfuels.1c00717

10. de Haas, T.W., Fadaei, H., and Sinton, D., Lab. Chip., 2012, vol. 12, pp. 4236.

https://doi.org/10.1039/c2lc40932a

11. Zhuang, Y., Goharzadeh, A., Lin, Y.J., Yap, Y.F., Chai, J.C., Mathew, N., Vargas, F., and Biswal, S.L., J. Pet. Sci. Eng., 2016, vol. 145, pp. 77-82. https://doi.org/10.1016/j.petrol.2016.03.017

12. Li, X., Guo, Y., Sun, Q., Lan, W., Liu, A., and Guo, X., J. Pet. Sci. Eng., 2018, vol. 162, pp. 333-340. https://doi.org/10.1016/j.petrol.2017.12.031 
13. Fadaei, H., Shaw, J.M., and Sinton, D., Energy Fuels, 2013, vol. 27. P., 2042-2048.

https://doi.org/10.1021/ef400027t

14. Fadaei, H., Scarff, B., and Sinton, D., Energy Fuels, 2011, vol. 25, pp. 4829-4835. https://doi.org/10.1021/ef2009265

15. Hasham, A.A., Abedini, A., Jatukaran, A., Persad, A., and Sinton, D., J. Pet. Sci. Eng., 2018, vol. 165, pp. 181-186. https://doi.org/10.1016/j.petrol.2018.02.017

16. Bowden, S.A., Wilson, R., Parnell, J., and Cooper, J.M., Lab. Chip., 2009, vol. 9, pp. 828-832. https://doi.org/10.1039/B814495H

17. Schneider, M.H., Sieben, V.J., Kharrat, A.M., and Mostowfi, F., Anal. Chem., 2013, vol. 85, pp. 5153-5160. https://doi.org/10.1021/ac400495x

18. Sieben, V.J., Tharanivasan, A.K., Andersen, S.I., and Mostowfi, F., Energy Fuels, 2016, vol. 30, pp. 1933-1946. https://doi.org/10.1021/acs.energyfuels.5b02216

19. Sohrabi, M., Danesh, A., and Jamiolahmady, M., Transp. Porous Media, 2008, vol. 74, pp. 239-257. https://doi.org/10.1007/s11242-007-9193-5

20. Doryani, H., Malayeri, M.R., and Riazi, M., Fuel, 2016, vol. 182, pp. 613-622. https://doi.org/10.1016/j.fuel.2016.06.004

21. Lin, Y.-J., He, P., Tavakkoli, M., Mathew, N.T., Fatt, Y.Y., Chai, J.C., Goharzadeh, A., Vargas, F.M., and Biswal, S.L., Langmuir., 2016, vol. 32, pp. 8729-8734. https://doi.org/10.1021/acs.langmuir.6b02376

22. Andanson, J.-M., Chan, K.L.A., and Kazarian, S.G., Appl. Spectrosc., 2009, vol. 63, pp. 512-517. https://doi.org/10.1366/000370209788347011

23. Martyanov, O.N., Larichev, Y.V., Morozov, E.V., Trukhan, S.N., and Kazarian, S.G., Russ. Chem. Rev., 2017, vol. 86, pp. 999-1023. https://doi.org/10.1070/RCR4742

24. Morozov, E.V. and Martyanov, O.N., Appl. Magn. Reson., 2016, vol. 47, pp. 223-235. https://doi.org/10.1007/s00723-015-0741-9

25. Miknis, F.P., Pauli, A.T., Michon, L.C., and Netzel, D.A., Fuel, 1998, vol. 77, pp. 399-405. https://doi.org/10.1016/S0016-2361(98)80030-6

26. Fisher, D.B., Espidel, J., Huerta, M., Randall, L., and Goldman, J., Transp. Porous Media, 1999, vol. 35, pp. 189-204.

https://doi.org/10.1023/A:1006578105518

27. Chala, G.T., Sulaiman, S.A., Japper-Jaafar, A., Kamil Wan Abdullah, W.A., and Mior Mokhtar, M.M., Int. J. Therm. Sci., 2014, vol. 86, pp. 41-47. https://doi.org/10.1016/j.ijthermalsci.2014.06.034

28. Christy, A.A., Dahl, B., and Kvalheim, O.M., Fuel, 1989, vol. 68, pp. 430-435. https://doi.org/10.1016/0016-2361(89)90263-9
29. Speight, J.G., Appl. Spectrosc. Rev., 1994, vol. 29, pp. 269-307. https://doi.org/10.1080/05704929408000561

30. Calemma, V., Iwanski, P., Nali, M., Scotti, R., and Montanari, L., Energy Fuels, 1995, vol. 9, pp. 225-230. https://doi.org/10.1021/ef00050a004

31. Coelho, R.R., Hovell, I., Moreno, E.L., de Souza, A.L., and Rajagopal, K., Pet. Sci. Technol., 2007, vol. 25, pp. 41-54. https://doi.org/10.1080/10916460601054198

32. Chibiryaev, A.M., Kozhevnikov, I.V., Shalygin, A.S., and Martyanov, O.N., Energy Fuels, 2018, vol. 32, pp. 2117-2127. https://doi.org/10.1021/acs.energyfuels.7b01630

33. Fossen, M., Kallevik, H., Knudsen, K.D., and Sjöblom, J., Energy Fuels, 2011, vol. 25, pp. 3552-3567. https://doi.org/10.1021/ef200373v

34. Tay, F.H. and Kazarian, S.G., Energy Fuels, 2009, vol. 23, pp. 4059-4067. https://doi.org/10.1021/ef900304v

35. Kazarian, S.G. and Chan, K.L.A., Appl. Spectrosc., 2010, vol. 64, pp. 135-152. https://doi.org/10.1366/000370210791211673

36. Chew, J., Joshi, H.M., Kazarian, S.G., MillanAgorio, M., Tay, F.H., and Venditti, S., Crude Oil Fouling, Elsevier, 2015, pp. 95-178. https://doi.org/10.1016/B978-0-12-801256-7.00004-X

37. Gabrienko, A.A., Lai, C.H., and Kazarian, S.G., Energy Fuels, 2014, vol. 28, pp. 964-971. https://doi.org/10.1021/ef402255c

38. Gabrienko, A.A., Subramani, V., Martyanov, O.N., Kazarian, S.G., Adsorpt. Sci. Technol., 2014, vol. 32, pp. 243-255. https://doi.org/10.1260/0263-6174.32.4.243

39. Gabrienko, A.A., Morozov, E.V., Subramani, V., Martyanov, O.N., Kazarian, S.G., J. Phys. Chem. C, 2015, vol. 119, pp. 2646-2660. https://doi.org/10.1021/jp511891f

40. Bunaciu, A., Fleschin, S., and Aboul-Enein, H., Curr. Anal. Chem., 2013, vol. 10, pp. 132-139. https://doi.org/10.2174/1573411011410010011

41. Sabbatini, S., Conti, C., Orilisi, G., and Giorgini, E., Biomed. Spectrosc. Imaging., 2017, vol. 6, pp. 85-99. https://doi.org/10.3233/BSI-170171

42. Ignatenko, V.Y., Kostina, Y.V., Antonov, S.V., and Ilyin, S.O., Russ. J. Appl. Chem., 2018, vol. 91, pp. 1835-1840. https://doi.org/10.1134/S1070427218110149

43. Shalygin, A.S., Kozhevnikov, I.V., Kazarian, S.G., and Martyanov, O.N., J. Pet. Sci. Eng., 2019, vol. 181, p. 106205 .

https://doi.org/10.1016/j.petrol.2019.106205

PETROLEUM CHEMISTRY Vol. 61 No. 92021 